\title{
RECENT RESEARCH ON THE GROWTH PLATE Mechanisms for growth plate injury repair and potential cell-based therapies for regeneration
}

\section{Rosa Chung and Cory J Xian}

School of Pharmacy and Medical Sciences, Sansom Institute for Health Research, University of South Australia, City East Campus, GPO Box 2471, Adelaide, South Australia 5001, Australia

Correspondence should be addressed to R Chung

Email

rosa.chung@unisa.edu.au

\begin{abstract}
Injuries to the growth plate cartilage often lead to bony repair, resulting in bone growth defects such as limb length discrepancy and angulation deformity in children. Currently utilised corrective surgeries are highly invasive and limited in their effectiveness, and there are no known biological therapies to induce cartilage regeneration and prevent the undesirable bony repair. In the last 2 decades, studies have investigated the cellular and molecular events that lead to bony repair at the injured growth plate including the identification of the four phases of injury repair responses (inflammatory, fibrogenic, osteogenic and remodelling), the important role of inflammatory cytokine tumour necrosis factor alpha in regulating downstream repair responses, the role of chemotactic and mitogenic platelet-derived growth factor in the fibrogenic response, the involvement and roles of bone morphogenic protein and Wnt/B-catenin signalling pathways, as well as vascular endothelial growth factor-based angiogenesis during the osteogenic response. These new findings could potentially lead to identification of new targets for developing a future biological therapy. In addition, recent advances in cartilage tissue engineering highlight the promising potential for utilising multipotent mesenchymal stem cells (MSCs) for inducing regeneration of injured growth plate cartilage. This review aims to summarise current understanding of the mechanisms for growth plate injury repair and discuss some progress, potential and challenges of MSC-based therapies to induce growth plate cartilage regeneration in combination with chemotactic and chondrogenic growth factors and supporting scaffolds.
\end{abstract}
Key Words
- growth plate injury
- cartilage tissue engineering
- chondrogenesis
- MSCs

Journal of Molecular Endocrinology (2014) 53, T45-T61

\section{The growth plate cartilage and endochondral bone formation}

Situated under the epiphysis at the ends of all long bones in an immature skeleton, the growth plate holds the sole responsibility in achieving longitudinal growth. It functions to produce a mineralised cartilaginous scaffold to which new trabecular bone is formed via a tightly controlled two-step process (called endochondral ossification) involving chondrogenesis and osteogenesis (Iannotti 1990, Yang \& Karsenty 2002).

The growth plate is made of three distinct zones, namely the resting zone, the proliferation zone and the hypertrophic zone (Iannotti 1990). The resting zone has previously been thought to play a very minimal role during

This paper is one of 4 papers in a thematic review section on Recent Research on the Growth Plate: Regulation, Injury and Regeneration. The guest editor for this section

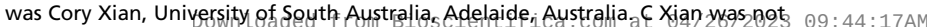
involved in the handling of this paper, on which they are listed as an author 
endochondral ossification as the pre-chondrocytes/ cells within this zone proliferate minimally (Forriol \& Shapiro 2005). However, studies have indicated the importance of the resting zone as it acts as a reservoir of stem cells/pre-chondrocytes for the chondrocytes in the adjacent proliferative zone (Abad et al. 2002). The proliferative zone is responsible for matrix production (including collagen-2 and aggrecan) and cellular division during endochondral ossification. The height of the proliferative zone directly correlates with the extent of longitudinal growth that can be achieved by the long bone (Iannotti 1990). As regulated by various signalling pathways including parathyroid hormone-related protein (Vortkamp et al. 1996), insulin-like growth factor (IGF1; Baker et al. 1993, Hunziker et al. 1994), bone morphogenic protein (BMP; Chen et al. 2004, Jing et al. 2013), Wnt/ B-catenin (Macsai et al. 2008, Dao et al. 2012, Golovchenko et al. 2013, Lu et al. 2013), fibroblast growth factor (FGF; Mancilla et al. 1998, Du et al. 2012) and others (Minina et al. 2002, Xian 2007), chondrocytes cease to proliferate and become hypertrophic. The hypertrophic chondrocytes produce collagen-10 which is involved with matrix mineralisation. Together with the action of angiogenic factor vascular endothelial growth factor (VEGF) produced by hypertrophic chondrocytes and a low oxygen tension, the lower hypertrophic zone attracts blood vessel invasion from the adjacent metaphyseal bone (Gerber et al. 1999, Forriol \& Shapiro 2005), which brings along mineralised cartilage-resorptive cells (chondroclasts), boneforming cells (osteoblasts) and bone-resorptive cells (osteoclasts) to convert the mineralised cartilage scaffold into trabecular bone in metaphysis.

\section{Growth plate injuries and their classification}

Being cartilaginous in nature and the weakest region of a long bone, the growth plate is often an injury-prone area. Past and recent epidemiological data have shown that $\sim 15-30 \%$ of all childhood skeletal injuries are growth plate related (Mizuta et al. 1987, Mann \& Rajmaira 1990, Eid \& Hafez 2002). While the prognoses in $\sim 40 \%$ of these growth plate-related injuries are fairly good, depending on the degrees and locations of fractures, those of others are not (Leary et al. 2009, Mubarak et al. 2009). In about 30\% cases, the injured growth plate cartilage is often repaired by an undesirable bony tissue (Ogden 1984, Barmada et al . 2003), which often results in substantial lifelong orthopaedic problems including discrepancies in limb length as well as bone angulation deformities (Ogden 1984, Wattenbarger et al. 2002).
The Salter-Harris classification system has been used to determine and predict the general outcome and severity of a growth plate injury (Brown \& DeLuca 1992). The classification system grades a growth plate injury into five types. Briefly, type 1 and 2 injuries (with type 2 being the most common injury type) do not disturb the growth plate or the epiphyseal blood supply and thus will usually heal by itself with no overall growth problems (Kay \& Matthys 2001, Leary et al. 2009). On the other hand, $\sim 30 \%$ of growth plate-related injuries are of types 3,4 or 5 , which disturb not only the growth plate but also its blood supply and hence usually lead to the undesirable bony repair (Sailhan et al. 2004, Basener et al. 2009).

\section{Growth plate injury repair responses}

In the past 2 decades, a number of animal models have been developed and used as attempts were made to understand the underlying pathophysiology for the faulty bony repair and to develop potential biological treatments, including the mouse and rat central drill hole disruption models (Lee et al. 2000, Xian et al. 2004, Coleman et al. 2010), rabbit peripheral disruption model (Lee et al. 1993, 1998, Planka et al. 2008), miniature pig peripheral disruption model (Planka et al. 2012) and sheep peripheral disruption model (Foster et al. 1990) (Fig. 1). In all of these models, bony repair and/or bone growth defects that mimic the human clinical outcomes can be demonstrated. In particular, in the last decade more extensive work using a rat proximal tibial drill hole model has been performed (Xian et al. 2004, Zhou et al. 2004, 2006, Arasapam et al. 2006, Chung et al. 2006, 2009, 2013a,b, 2014, Ngo et al. 2006, McCarty et al. 2009, 2010, Macsai et al. 2011, 2012), which has demonstrated different phases of injury repair that lead to the undesirable bony repair, namely the inflammatory, the fibrogenic, and the osteogenic and remodelling phases, on days $1-3,4-8$ and 8 onwards respectively (Fig. 2).

\section{The Inflammatory phase}

As in cases of all bone fracture and soft tissue injuries, the first phase of growth plate injury repair is the inflammatory phase, involving an infiltration of inflammatory cells (including neutrophils, monocytes/macrophages and lymphocytes) into the growth plate injury site and up-regulation of inflammatory cytokines and mediators (Zhou et al. 2004, Arasapam et al. 2006, Chung et al.

Published by Bioscientifica Ltd 


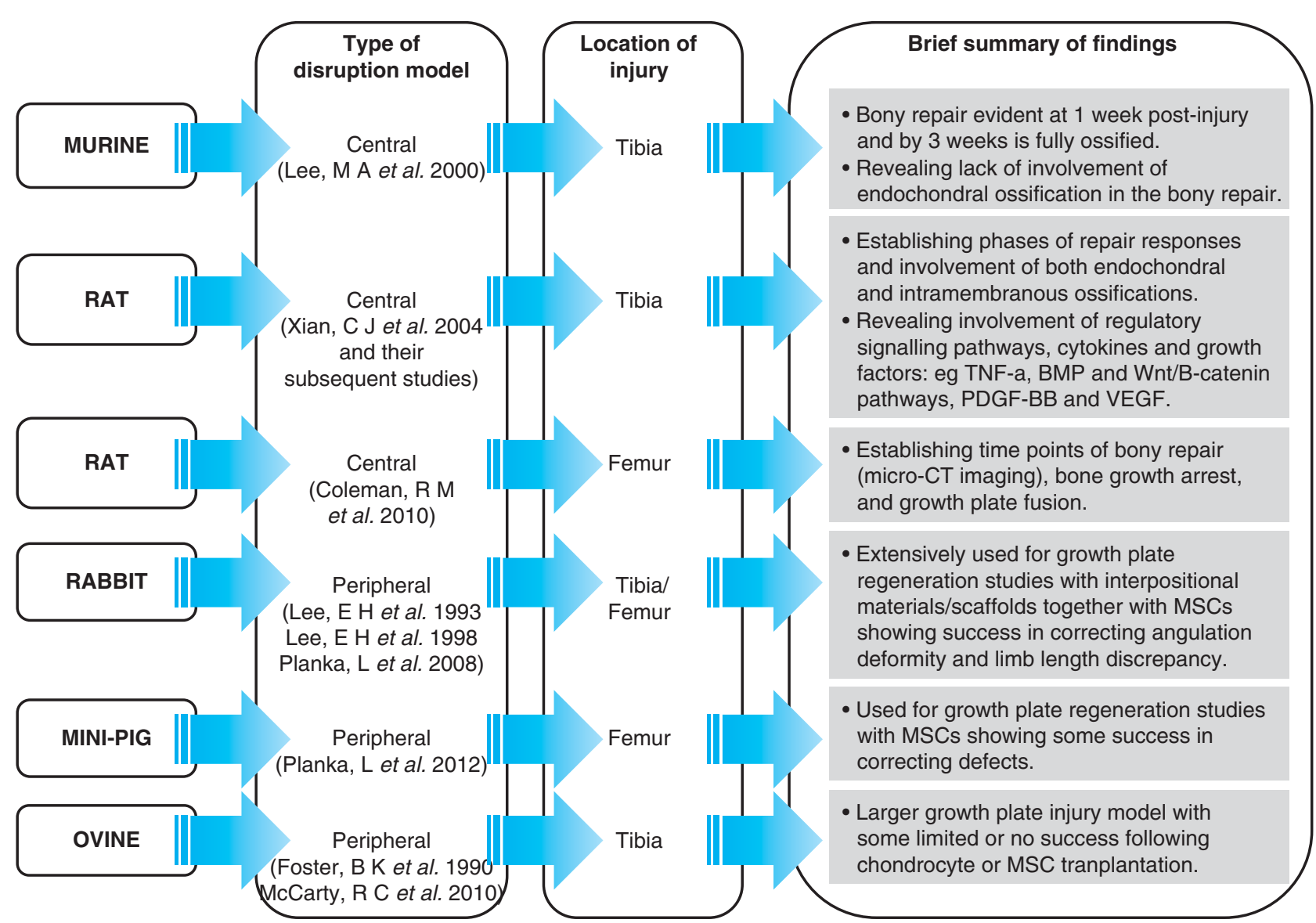

Figure 1

A brief summary of the different animal models used to study growth plate injury repair responses, mechanisms and regeneration.

2006). Consistent with a predominance of neutrophils within the influx, an increase in mRNA expression of neutrophil chemokine, Cinc1 (Cxcl1) (rat equivalent to human interleukin 8 (IL8)), was found on day 1, which declined on day 4 at the injured growth plate. Interestingly, neutrophil-mediated inflammatory response was found to modulate downstream injury repair events. Following the depletion of neutrophils with a neutralising antibody, Chung et al. (2006) observed an increase in the undesirable bony repair tissue with increased expression in bone-related genes such as Runx2 and osteocalcin, but decreased expression in cartilage-related genes Sox9 and collagen-2 (Chung et al. 2006).

In addition, up-regulation of some pro-inflammatory cytokines was also observed in this phase of injury response at the injured growth plate. Zhou et al. (2004) reported significant increases in the mRNA expression of tumour necrosis factor alpha (Tnf) and interleukin 1 beta (Il1b) (Zhou et al. 2004). Both of these cytokines are known to have roles in regulating inflammation after bone and soft tissue injuries (Feghali \& Wright 1997, Gerstenfeld et al. 2003). Moreover, at the injured growth plate, a higher level of activation of the major inflammatory mediator p38 kinase was observed, which was also found to be involved in TNFa and IL1B induction (Zhou et al. 2006). Utilising a TNFa antagonist in a rat growth plate injury model, Zhou et al. (2006) found that blocking TNFa resulted in a clear delay in the subsequent mesenchymal infiltration response and a reduction of the proliferation of these cells (Zhou et al. 2006). Similarly, separate studies looking at the role of TNFa during bone fracture repair and wound repair have also found that its inhibition leads to a significant delay in overall mesenchymal progenitor or stem cell (MSC) infiltration and subsequent healing (Gerstenfeld et al. 2001, Fu et al. 2009). More studies have reported the importance of TNFa in regulating recruitment of MSC, their proliferation and differentiation (Barnes et al. 1999, Martin et al. 2003, Dimitriou et al. 2005).

Furthermore, following growth plate injury, Arasapam et al. (2006) observed an increase in injury-induced

Published by Bioscientifica Ltd 

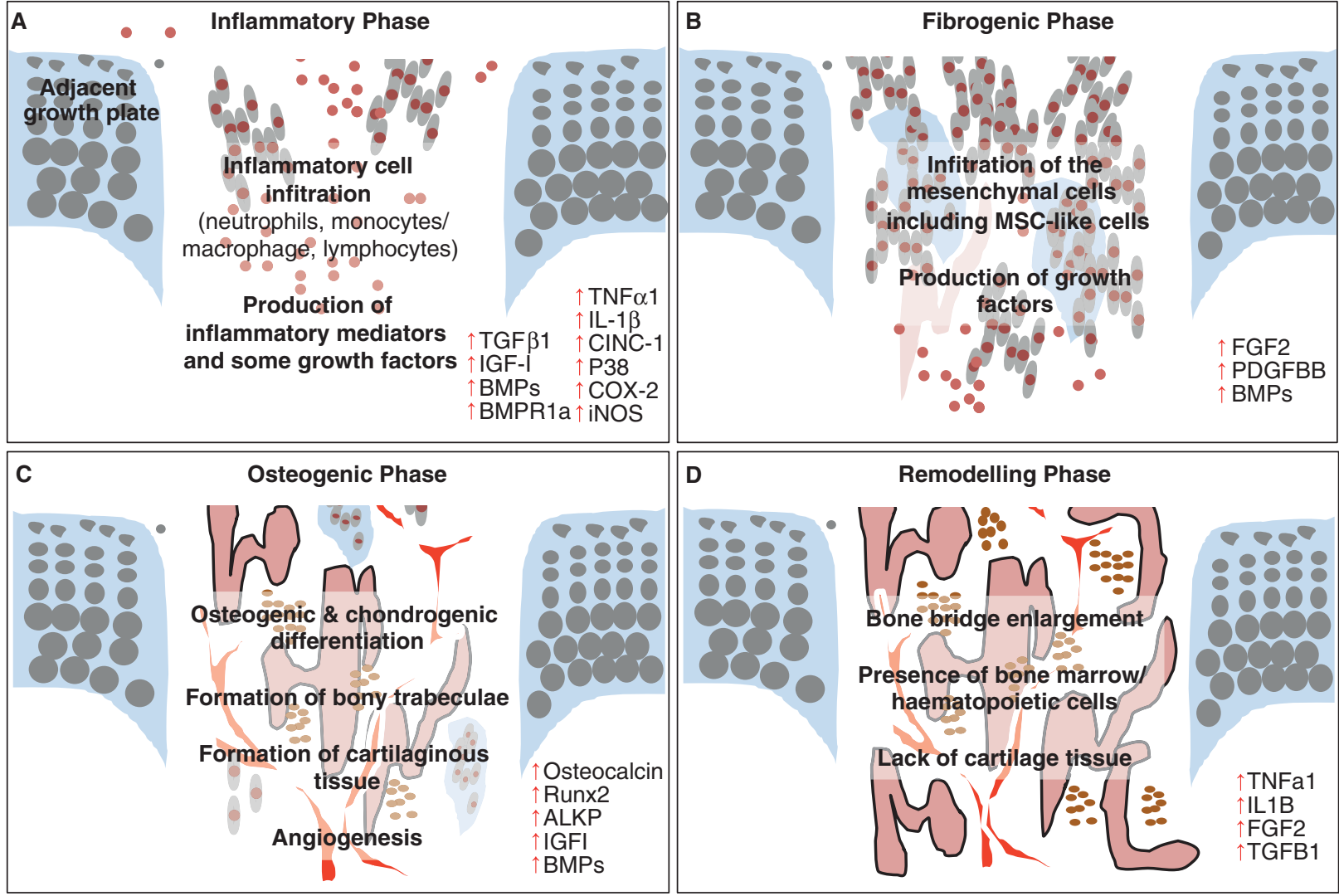

Figure 2

Injury repair response phases and their associated elevated cytokines, inflammatory mediators, growth factors, and molecules related to bone/ cartilage formation and remodelling that lead to the undesirable bony repair at the injury site in a rat tibial growth plate drill-hole injury repair model. The initial inflammatory response involves an influx of key inflammatory cells into the growth plate injury site and up-regulation of inflammatory cytokines/mediators and some growth factors (A).

inflammatory mediators, cyclooxygenase 2 enzyme, and inducible nitric oxide synthase. After blocking their activity pharmacologically, Arasapam et al. (2006) also found a decrease in chondrogenic differentiation of the infiltrated mesenchymal cells. Overall, the above studies indicate a potentially important role for the inflammatory phase, its cells, and released cytokines/mediators, not only in regulating the inflammatory phase itself but also in modulating downstream healing responses following growth plate injury.

\section{The fibrogenic phase}

Following the initial inflammatory phase, a fibrogenic phase is apparent at the growth plate injury site. The fibrogenic phase has been observed on days $3-7$ post-injury
The fibrogenic phase involves an influx of fibrogenic and progenitor cells containing MSC-like cells (B). The osteogenic phase involves the osteogenic and chondrogenic differentiation, formation of bony trabeculae together with angiogenesis within the injury site (C). The remodelling phase involves the maturation and active remodelling of the newly formed bony trabeculae as well as disappearance of cartilaginous repair tissue (D).

in injured growth plate of rats, involving an influx of vimentin (mesenchymal cell marker)-immunopositive mesenchymal cells (Xian et al. 2004), a response which is similar to the infiltration of mesenchymal cells following the inflammatory phase at bone fracture sites (Jaramillo et al. 1990, Schindeler et al. 2008). At the growth plate injury site, some of these cells were found to express growth factors including BMPs (Ngo et al. 2006), plateletderived growth factor (PDGF) and FGF2 (Zhou et al. 2004, Chung et al. 2009) and receptors for BMPs and PDGF (Ngo et al. 2006, Chung et al. 2009). In addition, some of these cells were found to be MSC like as they expressed the stem cell marker alpha-smooth muscle actin (Chung \& Burdick 2009). Furthermore, at the early time point day 4 post-injury, some of these cells already expressed chondrogenic marker collagen-2 and/or osteogenic marker

Published by Bioscientifica Ltd 
Runx2 (Xian et al. 2004, Chung et al. 2006), suggesting that this influx of mesenchymal cells may contain a myriad of cells including MSC-like cells, osteoprogenitor cells, pre-osteoblasts, and/or pre-chondroblasts (either pre-existing or newly derived from the infiltrated MSCs). Further indicative of potential multipotency for some of these cells, previous studies have shown that differentiation of these cells and growth plate repair outcomes could be influenced by some growth factors or other signals occurring during this phase (Arasapam et al. 2006, Chunget al. 2013a,b, 2014).

Alongside a myriad of signals at the growth plate injury or bone fracture site, the two more significantly up-regulated growth factors during this phase are PDGF and FGF2 (Zhou et al. 2004, Chung et al. 2009). In a rat growth plate injury model, Zhou et al. (2004) observed a significant peak in the mRNA expression of plateletderived growth factor $(P d g f)$ and fibroblast growth factor 2 ( $F g f 2$ ) following the initial inflammatory phase, suggesting a potential regulatory role for these two growth factors during this phase (Zhou et al. 2004). PDGFs in particular have been well documented to be involved in stimulating cell migration and proliferation as well as promoting angiogenesis during injury repair. In bone fracture repair, the chemotactic and mitogenic properties of PDGFs for mesenchymal cells and osteoblasts are essential for the initiation of correct bone fracture repair (Bordei 2011, Korsak et al. 2013, Elangovan et al. 2014). Similarly, in rats with growth plate injury, the inhibition of PDGF signalling caused a significant reduction in the amount of mesenchymal infiltrate, decreased amounts of bony and/or cartilage repair tissues, and thus an overall delay in bony repair 14 days post-injury (Chung et al. 2009), highlighting the importance of PDGF expression during growth plate injury repair in regulating the fibrogenic phase and downstream tissue repair processes. More studies are still needed to further elucidate the specific role of PDGF and other signal molecules occurring during this phase of growth plate injury repair.

\section{The osteogenic and remodelling phases}

At the injured growth plate, bone formation has been observed to commence around day 7 with the appearance of bony trabeculae, and bone remodelling has been observed by day 14 with the appearance of bone marrow cells in between bony trabeculae (Xian et al. 2004). A recent in vivo micro-computed tomography (micro-CT) imaging study has demonstrated that the bone volume fraction of the injury site was significantly higher on day 60 when compared with that on day 14 (Macsai et al. 2011). During the osteogenic phase of the growth plate injury repair process, the cells within the fibrogenic infiltrate differentiate into Runx2 and alkaline phosphatase-immunopositive osteoblasts (Xian et al. 2004, Arasapam et al. 2006, Chung et al. 2006, 2009, Zhou et al. 2006) and produce increased levels of bone matrix protein osteocalcin (both mRNA and protein) during days 8-14 (Xian et al. 2004, Arasapam et al. 2006). Similarly, Fischerauer et al. (2011) also observed collagen-1-immunopositive bone tissue at the injury site $\sim 14$ days post-growth plate injury (Fischerauer et al. 2011). On day 35, histologic examination of the injury site has also revealed the presence of flattened inactive bone-lining osteoblasts that weakly expressed osteocalcin (Xian et al. 2004).

In addition, starting at day 14 , there were also signs of bone remodelling, with the presence of multi-nucleated osteoclasts lining the newly formed bone trabeculae (Chung et al. 2009). During the bone remodelling phase, levels of osteocalcin mRNA expression were found increased, and expression of chondrogenesis-related genes such as Sox9 and collagen-2a was lacking (Zhou et al. 2004). In addition, Tnfa (Tnf) mRNA expression was found increased during the remodelling phase (Zhou et al. 2004), which is similar to that seen during the bone maturation and remodelling phase of bony fracture repair (Gerstenfeld et al. 2001). Previously, TNFa has been associated with bone remodelling by promoting osteoclast differentiation (Horowitz et al. 2001). In addition, Fischerauer et al. (2011) have also observed an increase in expression of VEGF (VEGFA) (Fischerauer et al. 2011). VEGF has known roles not only in angiogenesis but also in osteoblast differentiation and osteoclast recruitment (Yang et al. 2012). The above studies indicate the active involvement of bone formation and remodelling within the growth plate injury site that lead to the formation of the undesirable bony repair tissue or bone bridge; however, more studies are required to characterise the specific molecular and cellular events that regulate these and bone bridge formation.

\section{Potential changes at the adjacent non-injured region of the growth plate}

Although a myriad of studies have investigated the phases of events that occur within the growth plate injury site, it is only recently that more interest has been shown on the potential effects of growth plate injury on the adjoining uninjured adjacent growth plate cartilage. Previous studies have suggested that injuries in the long bone can

Published by Bioscientifica Ltd 
inadvertently affect the tightly controlled process of endochondral ossification in the growth plate. These effects were found regardless whether the growth plate was injured or not. For example, Fischerauer et al. (2013) found that following a tibial fracture, there were up-regulated levels of BMP6 and BMP receptor BMPR1A at the growth plate of the fractured or the contralateral intact bones on day 29 (when fractured bone was consolidated), suggesting possibly a late role of BMP6 and BMPR1A in bone fracture-induced growth plate alterations and the potential existence of a regulatory 'cross-talk' mechanism between the different regions of the lower limbs after bone fractures (Fischerauer et al. 2013). A recent study by Macsai et al. (2011) evaluated injured growth plate of rats by micro-CT (Macsai et al. 2011) and found the presence of small bony 'tethers' at the uninjured adjacent growth plate on day 60 post-injury. These 'tethers' were not observed in age-matched non-injured animals, suggesting that the growth plate injury itself affected not only the injury site but also the surrounding areas.

In addition, further analysis of the adjacent growth plate also revealed that following growth plate insult, the uninjured adjacent cartilage had a significant reduction in chondrocyte proliferation but an increase in apoptosis (Macsai et al. 2011). Macsai et al. (2011) also observed that the adjacent growth plate showed decreases in expression of chondrogenic transcription factor Sox9 and growth factors TGFB1 and IGF1 in comparison to their non-injured controls (Macsai et al. 2011). Similarly, Musumeci et al. (2013) also reported an increase in expression of apoptotic marker, caspase- 3 protein, over days 7-30 post-injury in the adjacent growth plate of their experimental rats (Musumeci et al. 2013), although this study did not use an antibody that distinguishes between the intact inactive and cleaved active forms of caspase- 3 . Musumeci et al. (2013) suggest that one potential mechanism for this histomorphological change at the adjacent growth plate may be related to the observed increase in levels of inflammatory cytokine TNFa during the bony repair tissue formation at the growth plate injury site (Musumeci et al. 2013). While the above studies have demonstrated that the growth plate injury also affects the uninjured adjacent areas of growth plate, the current evidence is quite limited. So far, there has been no evidence reported whether and how the alterations in the adjacent area of growth plate can affect bone growth. More studies are required to characterise cellular and molecular changes that lead to the bone formation at the adjacent cartilage and whether and how these changes contribute to the final bone growth defect outcomes.

\section{Vascularisation of the growth plate injury site in bone bridge formation}

Angiogenesis is critical for endochondral bone growth, bone modelling, bone remodelling, and fracture repair (Brandi \& Collin-Osdoby 2006, Chim et al. 2013). It is known that, after a 'fibrous tissue' is formed from the infiltrated stromal cells at an injured growth plate, its invasion by new blood vessels is a prerequisite for its osseous transformation (Odgen 2000). While the process of vascularisation is vital for the formation of new bone tissue and bony repair following growth plate injuries, the molecular mechanism for the growth plate injury site angiogenesis remains unclear.

VEGF is a known key mediator of angiogenesis and has roles in both bone-forming processes - direct (intramembranous) and indirect (endochondral ossification) (Emad et al. 2006, Dai \& Rabie 2007, Li et al. 2009). Highlighting VEGF's essential role during bony repair, Street et al. (2002) found that in a mouse bone fracture model, the absence of VEGF delayed bone formation by halting the initial soft callus from being converted into hard bony callus. Interestingly, in a rat growth plate injury study, VEGF was detected as early as days 1 and 3 post-injury, suggesting that VEGF may have roles in the repair process to form the bony repair tissue (Fischerauer et al. 2011). A recent study has examined the potential role of VEGF-induced angiogenesis on bony tissue formation at the injured growth plate. Using a rat growth plate injury model and applying an anti-VEGF antibody treatment immediately following surgery, Chung et al. (2014) found that the numbers of blood vessel-like structures were significantly decreased at the growth plate injury site. Importantly, anti-VEGF treatment was found to increase the amount of undifferentiated mesenchymal tissue infiltrate remaining and to decrease the bony tissue present at the growth plate injury site. Consistently, gene expression analysis revealed significant decreases in expression of bone-related genes such as osteocalcin at the growth plate injury site (Chung et al. 2014). Overall, this study suggests that VEGF is vital for not only angiogenesis but also the formation of bony repair tissue at the growth plate injury site. This finding may present a potential target of intervention for developing biological therapies to block bone bridge formation at the injured growth plate (Chung et al. 2014).

Published by Bioscientifica Ltd 


\section{Mechanisms of bony repair tissue formation at the injured growth plate}

\section{Intramembranous and endochondral ossification}

Earlier rodent growth plate injury repair studies have suggested the intramembranous bone formation mechanism at the injured growth plate as examined at some time points. Lee et al. (2000) in a mouse model observed no changes in expression of endochondral ossification-related genes such as collagen-2, Vegf, or Indian hedgehog (Ihh). Using a similar drill hole growth plate injury model in rats, Xian et al. (2004) and Zhou et al. (2004) observed the presence of Runx2-immunopositive osteoblasts during the formation of bony trabeculae within the growth plate injury site and no up-regulation in chondrogenesis-related genes such as Sox9 and collagen-2 (Xian et al. 2004, Zhou et al. 2004). However, following on from these studies, others have shown that in addition to the direct bone formation mechanism, the endochondral ossification indirect bone formation was also in play in some time points examined. Several studies in the rat growth plate injury model found increases in cartilage-related genes such as Sox9 and collagen-2 alongside the increased expression in bone-related genes such as Runx2 and osteocalcin (Arasapam et al. 2006, Chung et al. 2006, 2009). More importantly, significant increases in expression of collagen-10 were observed (Arasapam et al. 2006, Chung et al. 2006, 2009). Collagen-10 is expressed by hypertrophic chondrocytes during endochondral ossification. These studies thus indicate that both mechanisms of bone formation may be involved during growth plate bony repair.

\section{Osterix and the involvement of protein kinase D during bony repair}

Osteogenic transcription factors, Runx 2 and osterix, are well known to be essential for osteoblast differentiation during embryonic development (Komori et al. 1997, Nakashima et al. 2002, Day et al. 2005) and during postnatal bone growth and homeostasis (Zhou et al. 2010). In addition, increased osterix expression has been observed during bone fracture healing, and osterix overexpression can induce bone healing (Tu et al. 2007, Xu et al. 2009). A recent study examined the potential role of osterix in mediating the bony repair tissue formation following growth plate injury. Chung et al. $(2013 a, b)$ utilised a synthetic inhibitor, gö6976, to block protein kinase D (PKD) during growth plate injury repair in a rat model. PKD has previously been shown to up-regulate osterix and be important for osteoblast differentiation (Celil \& Campbell 2005, Jensen et al. 2009). This study found that inhibition of PKD suppressed bony repair but induced more chondrogenic differentiation at the injury site (Chung et al. 2013a,b). Consistent with this finding, Kaback et al. (2008) found that the over-expression of osterix in osteochondroprogenitor cells resulted in a decrease in chondrogenic transcription factor Sox9. These studies suggest that osterix may have a role in inhibiting chondrogenic differentiation while encouraging osteoblast differentiation. However, more studies are required to elucidate the role and importance of PKD and osterix during growth plate bony repair, and whether PKD and osterix may potentially be a target for interventions to block bony repair but to increase cartilage healing following growth plate injury.

\section{Involvement of BMP and Wnt signalling pathways for the growth plate bony repair}

BMPs are known key regulators for skeletal repair (Sakou 1998). In particular, BMP2 is consistently up-regulated during the initial stages of bone fracture healing (Yaoita et al. 2000, Marsell \& Einhorn 2009) and, as shown by mutant mouse studies, is critical for bone fracture healing (Tsuji et al. 2006). In addition to its role in the recruitment of osteoprogenitor cells into a bone fracture site, BMP signalling is ultimately required for their differentiation into osteoblasts (Ghodadra \& Singh 2008). Therapeutically, BMP2 has been shown to induce the bone healing response in many animal models of critical-sized segmental non-union defects in both small and large animals (Kirker-head \& Gerhart 1998, Murakami et al. 2002). However, roles of BMPs in growth plate repair remain largely unknown and have only started to be addressed recently. In a rat tibial drill hole growth plate injury model, levels of $B m p 2$ mRNA expression were found notably increased in the early part of the fibrogenic phase and then again later during the osteogenic phase (Macsai et al. 2012). Similarly, Ngo et al. (2006) also detected BMP2 protein expression immunohistochemically within the injury site during the fibrogenic and osteogenic responses. Furthermore, a microarray study of a rat growth plate injury model has also identified BMP signalling pathway as one of the most active pathways during the osteogenic phase of the bony repair of the injured growth plate (Macsai et al. 2012). Overall, these gene expression studies suggest that BMP signalling may play an important role in regulating or mediating the

Published by Bioscientifica Ltd 
formation of the undesirable bony repair tissue at the injured growth plate, and further intervention studies are required to confirm whether indeed BMP signalling (particularly from BMP2) is required for the growth plate bony repair.

Another known integral signalling pathway during bone formation and fracture repair is the Wnt/B-catenin signalling pathway (Day et al. 2005, Chen et al. 2007, Macsai et al. 2008). Similarly, recent studies have demonstrated that Wnt/B-catenin signalling pathway is also important for growth plate bony repair (Macsai et al. 2012, Chung et al. 2013a,b). In a rat model study, B-catenin expression levels were found to be significantly up-regulated on day 4 in comparison to day 8 post-injury, and the Wnt/B-catenin signalling pathway was identified as one of the most active pathways involved in the growth plate bony repair (Macsai et al. 2012). More recently, when the Wnt/B-catenin signalling pathway was inhibited using a B-catenin inhibitor in rats within the growth plate injury, Chung et al. $(2013 a, b)$ observed a significant decrease in proportion of bony repair tissue and coincidently an increase in chondrogenic differentiation within the injury site. Overall, with their notable essential roles in bone fracture healing, the above studies strongly suggest that both BMP and Wnt/B-catenin signalling pathways are important in regulating the growth plate bony repair. However, further studies are required to confirm this, to investigate their action mechanisms, and to explore whether they can be potential targets for interventions to block bony repair but to enhance cartilage regeneration.

\section{Current corrective treatments for growth plate injuries}

Currently, there are no known biological therapies for the prevention of bony repair following growth plate injuries. At this present time, dependent on the severity and types of the injury, bone growth defect outcomes, and the age of the patient, some bone growth defects resulting from growth plate injuries are managed by corrective surgeries, including limb lengthening and interpositional implantation of materials. Limb lengthening is used to correct limb length discrepancies using an external frame or scaffold such as the Ilizarov frame to stabilise and stretch the limb following surgical fracturing. However, requiring multiple pins and involving an invasive surgically created fracture, this procedure is riddled with issues such as pin site infections and lengthy lengthening time. More recently, another bone lengthening procedure using an internally implanted nail called 'Fitbone' is being utilised (Baumgart 2009), but it can only be used in adults. Furthermore, bone angulation deformities are often treated via the insertion of various interpositional materials following the surgical removal of bony repair tissue at the growth plate injured site. Referred to as the Langenskiold method (Langenskiold 1981), this procedure has previously been done with various interpositional materials for implantation, including fat, muscle, bone wax, cement and polymeric silicone materials (Tobita et al. 2002). Currently, there have been no biological treatments that are clinically used to prevent the growth plate faulty repair and to prevent the associated bone growth defects. However, in the last 2 decades, various experimental studies have been carried out attempting to develop chondrocyte or MSC-based biological therapies for growth plate regeneration.

\section{Previous studies and current advances in cartilage tissue engineering for growth plate regeneration}

Advances in cartilage tissue engineering include developments in areas such as autologous cell transfers, direct chondrocyte transplantations, MSC transplantations, as well as advances in the way these are implanted into the desired sites using various carriers such as natural biomaterials, synthetic materials and hydrogel scaffolds in combination with a cocktail of chemotactic and cartilage-inducing growth factors. In addition, in more recent years the focus has also shifted in potentially utilising the patient's own endogenous MSCs to initiate a more desirable chondrogenic repair. The following sections have outlined some of these advances directly in relation to growth plate injury repair (Table 1).

\section{Chondrocyte transplantation and the regeneration of injured growth plates}

Owing to the difficulty in regenerating cartilage, earlier studies have attempted cartilage repair via allogeneic or autologous chondrocyte transplantations. The concept of this transplantation involves the collection of healthy chondrocytes from a donor or patient, the ex vivo expansion, followed by their re-implantation into the patient. As allogeneic chondrocyte transplantation involves the removal of chondrocytes from one host followed by the transplantation of chondrocytes into another host (Toolan et al. 1998), it has the obvious disadvantages of the high risk of disease transmission from one source to the other

Published by Bioscientifica Ltd 
Table 1 A summary of experimental studies of cell therapies for growth plate regeneration

\begin{tabular}{|c|c|c|c|c|c|}
\hline Animal model & Cell type & Growth factor used & Scaffold used & Effect observed & Reference \\
\hline Rabbit & $\begin{array}{l}\text { Cultured } \\
\text { chondrocytes }\end{array}$ & - & Agarose $(0.3 \%)$ & $\begin{array}{l}\text { Decreased bone angulation and } \\
\text { length difference compared } \\
\text { with agarose alone }\end{array}$ & Lee et al. (1998) \\
\hline Rabbit & - & $\begin{array}{l}\text { adIGF1 and } \\
\text { adBMP2 vectors }\end{array}$ & $\begin{array}{l}\text { Muscle } \\
\text { interposition }\end{array}$ & $\begin{array}{l}\text { adIGF1, decreased limb length } \\
\text { discrepancy and adBMP2, bone } \\
\text { bridge formed }\end{array}$ & Lee et al. (2002) \\
\hline Rabbit & $\begin{array}{l}\text { MSC from } \\
\text { periosteum }\end{array}$ & - & Agarose & $\begin{array}{l}\text { Limb angulation and length } \\
\text { corrected }\end{array}$ & Chen et al. (2003) \\
\hline Rabbit & BMMSCs & $\begin{array}{l}\text { hTGFB3 } \\
\quad(10 \mathrm{ng} / \mathrm{ml})\end{array}$ & $\begin{array}{l}\text { Porcine skin } \\
\text { gelatin }\end{array}$ & $\begin{array}{l}\text { Degree of angulation deformity } \\
\text { was reduced }\end{array}$ & Anh et al. (2004) \\
\hline Rabbit & $\begin{array}{l}\text { MSC from } \\
\text { periosteum }\end{array}$ & - & Chitin & Reduced length discrepancy & Li et al. (2004) \\
\hline Rabbit & BMMSCs & $\begin{array}{l}\text { hTGFB1 } \\
\quad(100 \mathrm{ng} / \mathrm{ml})\end{array}$ & $\begin{array}{l}\text { Hyaluronan and } \\
\text { collagen-1 }\end{array}$ & $\begin{array}{l}\text { Limb lengthening increased and } \\
\text { angulation was decreased } \\
\text { compared with scaffold alone }\end{array}$ & Planka et al. (2008) \\
\hline Rabbit & - & $\begin{array}{l}\text { hIGF1 } \\
\qquad(5.9 \mu \mathrm{g} / \mathrm{scaffold})\end{array}$ & PLGA scaffold & $\begin{array}{l}\text { Histology revealed regeneration } \\
\text { of cartilage (disorganised) }\end{array}$ & $\begin{array}{l}\text { Sundararaj et al. } \\
\quad(2012)\end{array}$ \\
\hline Miniature pig & BMMSCs & - & $\begin{array}{c}\text { Chitosan and } \\
\text { collagen-1 }\end{array}$ & $\begin{array}{l}\text { Limb length was greater } \\
\text { compared with scaffold alone }\end{array}$ & Planka et al. (2012) \\
\hline Miniature pig & Chondrocytes & - & $\begin{array}{c}\text { Chitosan and } \\
\text { collagen-1 }\end{array}$ & $\begin{array}{l}\text { Limb angulation was reduced } \\
\text { compared with scaffold alone }\end{array}$ & Planka et al. (2012) \\
\hline Ovine & BMMSCs & $\begin{array}{l}\text { hTGFB1 } \\
\quad(10 \mathrm{ng} / \mathrm{ml})\end{array}$ & Gelfoam sponge & $\begin{array}{l}\text { Undesirable fibrous tissue } \\
\text { formation at the injury site }\end{array}$ & McCarty et al. (2010) \\
\hline In vitro & hBMMSCs & $\begin{array}{l}\text { hTGFB1 and } \\
\text { hBMP2 }\end{array}$ & Agarose & $\begin{array}{l}\text { Cells differentiated into growth } \\
\text { plate-like structure }\end{array}$ & Schmitt et al. (2012) \\
\hline
\end{tabular}

(Detterline et al. 2005). Autologous chondrocyte transplantation, on the other hand, requires the removal of chondrocytes from one host followed by the re-implantation of ex vivo-expanded cells back into the same host.

Early experimental work showed that ex vivo-expanded chondrocytes can be successfully transplanted into a growth plate injury site and are able to form the growth plate-like columnar structures in a rabbit model (Bentley \& Greer 1971). Similarly using rabbit models, Lee et al. (1998) showed that transplantation of ex vivo-expanded chondrocytes to the injury site can eliminate growth arrest and angulation deformities in treated limbs compared with the injured, untreated control limbs. In addition, they observed similar effects when the chondrocytes were either implanted immediately after the growth plate injury, or implanted following surgical removal of an existing bone bridge formed following a growth plate injury induced earlier (Lee et al. 1998). More recently, Jin et al. (2006) and $\mathrm{Li}$ et al. (2013) also in a rabbit growth plate injury model reported success in restoring the growth plate to its original form, preventing bone bridge formation and in possibly preventing early ossification and closure of the growth plate following transplantation of chondrocytes (Jin et al. 2006) or chondrocytes that were microencapsulated (Li et al. 2013) using a semipermeable membrane shown to be able to reduce potential transplantationassociated immunological reactions (Koo et al. 2008, Revell $\&$ Athanasiou 2009).

Although many studies (including the above) have shown some degree of success in repairing the injured growth plate, it is interesting to highlight that the majority of these were done in rabbit growth plate injury models. However, one earlier study by Foster et al. (1990) performed in a larger ovine model suggested that chondrocytes directly isolated from the growth plate may possibly be used as an interpositional material after growth plate injury since the implanted chondrocytes prevented bone bridge formation (Foster et al. 1990). However, although the concept of chondrocyte transplantation may be promising and may be potentially useful for many situations requiring cartilage repair such as in arthritis, this technique's suitability remains questionable realistically in inducing regeneration of injured growth plate cartilage in humans. This is due to the source limitations with chondrocyte harvest, the time taken for the collection, and ex vivo expansion followed by the re-implantation into the injury site (Miura et al. 2002). By the time the chondrocytes are ready to use, it is likely that the growth plate injury site has already formed the undesirable bony repair. Thus an alternative source of cells or a different approach of

Published by Bioscientifica Ltc 
therapy is much needed for the prevention of the undesirable bony repair and regeneration of growth plate cartilage following growth plate injury in humans.

\section{MSCs for growth plate injury repair}

Owing to the limited feasibility of utilising chondrocyte transplantation techniques for the regeneration of growth plate cartilage, more recent studies have focussed on the suitability of utilising adult MSCs. Adult MSCs are capable of differentiating into cells of many tissues such as cartilage, bone, and fat. In addition, MSCs can be isolated from many different sources, including the periosteum, trabecular bone, adipose tissue, synovium, skeletal muscle, as well as the bone marrow (Xian \& Foster 2006, McCarty et al. 2009). Interestingly, previous studies have observed that synovium-derived MSCs in particular had the greatest capability to enhance the chondrogenic differentiation potential when compared with any other mesenchymal tissue-derived cells (Sakaguchi et al. 2005). However, other studies have reported that bone marrowderived MSCs (BMMSCs) are most suitable for cartilage tissue engineering, as they possess higher proliferation rates and higher levels of expression of cartilage-specific genes, when compared with MSCs derived from other tissues (Park et al. 2006, Schmitt et al. 2012). In addition, due to their location and abundance, BMMSCs in particular seem ideal for growth plate cartilage regeneration (Caplan 1991, Provot \& Schipani 2005, Xian \& Foster 2006). More recently, MSCs were successfully isolated directly from murine epiphysis. Cheng et al. (2012) suggest that this novel type of MSCs could potentially be better than BMMSCs as they have shown greater capacities in growth and differentiation potential as well as possessing immunosuppressive and antiinflammatory properties (Cheng et al. 2012).

In the last decade, studies have looked into the possibility and suitability of applying MSCs for inducing growth plate cartilage regeneration. Chen et al. (2003) observed that MSCs derived from the periosteum were able to completely correct bone angulation as well as regenerate the growth plate in a rabbit model (Chen et al. 2003). Hui et al. (2005) also reported some success in utilising MSCs to decrease limb length discrepancy in a rabbit model (Hui et al. 2005). Similarly, Yoshida et al. (2012) found less bone bridge formation and reduced limb length discrepancies following implantation of synovium-derived MSCs into a rabbit growth plate injury model (Yoshida et al. 2012). In addition to the above smaller animal models, Planka et al. (2012) also recently implanted allogeneic MSCs into a miniature pig growth plate injury model and found that some growth disturbances were able to be prevented in addition to a decrease in bone angulation deformities. Planka et al. (2012) also observed repair tissue at the injury site being similar to hyaline cartilage with possible growth plate-like column structures. In a larger ovine growth plate injury repair model, McCarty et al. (2010) studied the efficacy of autologous MSC transplantation in repairing the injured growth plate. Following the transplantation of autologous MSCs into a proximal tibial growth plate injury site, McCarty et al. (2010) observed no increase in cartilage tissue formation 5 weeks post-transplantation. Instead, there was an increase in fibrous tissue formation in the animals treated with MSCs. The authors, however, highlighted that the transplantation did not increase the amount of osteogenesis or undesirable bony repair tissue. So far, although there have been some advances in utilising MSCs for growth plate regeneration, attenuation of undesirable bony repair, and/or prevention of the associated angulation and limb length deformities, these have been achieved mainly in the rabbit models. The lack of cartilage regeneration induced by autologous MSCs in the ovine growth plate injury model (McCarty et al. 2010) has highlighted that more work is needed to explore the potential of MSCs for growth plate regeneration in large animal models.

\section{Challenges and future prospects for growth plate regeneration using MSC-based therapy}

Similar to most tissue engineering/cell-based therapies for bone/articular cartilage repair, more work is required to optimise strategies to solve the three major requirements for successful growth plate cartilage regeneration: optimal sources of MSCs and their expansion; optimal signal molecules that induce chondrogenesis; and matrix scaffold that supports cartilage regeneration and recovery of growth plate zonal structure. Although limited, growth plate cartilage regeneration-specific studies have shown some success in various animal models when used in combination with cells such as MSCs, chondrogenic growth factors and supporting scaffolds (Table 1).

\section{MSCs and their sources for growth plate regeneration}

Specific for growth plate regeneration, the suitability of the MSCs seems to rely heavily on their source of isolation. Using a rabbit growth plate injury model, Hui et al. (2005) compared the effectiveness of MSCs of different sources for growth plate regeneration and found that MSCs isolated from both the bone marrow and periosteum were able to

Published by Bioscientifica Ltd 
correct the angulation and prevent further bony repair and to differentiate into organised growth plate-like chondrocytes at the injury site. On the other hand, treatment with MSCs that were isolated from adipose tissue formed disorganised chondrocytes within the growth plate injury site of the rabbits (Hui et al. 2005). Furthermore, Planka et al. (2008) examined the differences in suitability and efficiency of both autologous and allogeneic transplanted MSCs and found no significant differences between the two types of MSC transplantations in correcting limb length discrepancy and angulation as well as phenotype of the cartilage repair tissues formed within the growth plate injury site in rabbits.

In addition to finding the most appropriate source of MSCs for growth plate regeneration, another clinical challenge involves getting sufficient amounts of cells for implantation. As chondrogenic differentiation favours a dense and packed cell environment, MSC transplantation of a lesser cell density may not create a favourable environment for optimal growth plate regeneration. Current animal models showing significant repair effects on angulation, length discrepancy and chondrocyte regeneration have utilised cell numbers between $1.6 \times 10^{6}$ and $4 \times 10^{6}$ cells depending on the size of defects and types of the animal models (Ahn et al.2004, Hui et al. 2005, McCarty et al. 2010). However, finding an optimal cell density and optimising conditions for MSC in vitro expansion to achieve a clinically relevant number of cells for implantation still need to be thoroughly investigated for successful growth plate cartilage regeneration.

\section{Growth factors or their combination for growth plate regeneration using MSCs}

MSCs are heavily influenced by and require signals (particularly growth factors) for their migration, proliferation and differentiation. In regard to growth plate cartilage repair, ideally, a combination of growth factors would firstly assist with optimal expansion of MSCs and then with the induction of chondrogenic differentiation. Some of the growth factors that have previously been studied for their MSC mitogenic properties include PDGF, IGF1, FGF2 and TGFa (McCarty et al. 2009), and growth factors with known chondrogenic properties include FGF2, TGFB1, TGFB3, BMP7 and IGF1 (Lennon et al. 1995, Yamaguchi 1995, Johnstone et al. 1998, Worster et al. 2000, 2001, McCarty et al. 2009). FGF2 has been shown to have potent mitotic properties as well as encouraging MSCs differentiating towards a chondrogenic differentiation (Solchaga et al. 2005). Moreover, rat BMMSCs that were initially treated with FGF2 during cell expansion underwent chondrogenesis once placed in a 3D agarose gel together with TGFB1 (Coleman et al. 2007, 2013). On the other hand, cells that were not treated with FGF2 resulted in no production of cartilaginous matrix even with the addition of TGFB1 (Coleman et al. 2013). Fukumoto et al. (2003) found that TGFB was able to induce a $20 \%$ increase in chondrogenesis in MSCs in an in vitro chondrogenic assay. TGFB3 has been shown to stimulate chondrogenic differentiation as well as increase the expression of various cartilage matrix molecules in MSCs (Indrawattana et al. 2004, Tang et al. 2009). Ahn et al. (2004) reported success in reducing angular deformity in a rabbit growth plate injury model using TGFB3 alongside MSCs embedded in Gelfoam. However, when repeated in a larger animal model, these reported chondrogenic effects of MSCs and TGFB1 were not found in an ovine growth plate injury model (McCarty et al. 2010).

In order to elicit a more potent chondrogenic differentiation response from MSCs, the combinational use of growth factors can often increase chondrogenesis. Fukumoto et al. (2003) showed that by combining TGFB1 and IGF1, a significant $20 \%$ increase in cartilage production was observed when compared with treatment with either growth factor alone. This enhancing effect is thought to be related to the fact that while IGF1 is essential for the differentiation and maturation of growth plate chondrocytes, TGFB is more useful in inducing chondrogenesis (Indrawattana et al. 2004, Jaklenec et al. 2008). McCarty et al. (2009) also found that the combination of BMP7 with TGFB1 produced larger chondrogenic pellets when compared with those treated with TGFB1 alone. Overall however, more studies are needed to further identify the most optimal mixture of growth factors as well as their delivery to better induce growth plate cartilage regeneration from MSCs.

\section{Matrix scaffolds for growth plate regeneration using MSCs}

In addition to growth factors, another challenge for growth plate regeneration is to find the most appropriate carrier support systems (matrix scaffolds) for MSC transplantation and their chondrogenic differentiation. A matrix scaffold essentially acts as a support structure for MSCs, as a delivery and stability vehicle for growth factors, as well as influencing the eventual differentiation of these cells. Ideally, they should be biodegradable, biocompatible, promoting cell attachment, as well as allowing for tissue formation (Hutmacher 2000, Drury \& Mooney 2003). Planka et al. (2012) embedded MSCs into a chitosan and collagen combined scaffold. Following the implantation of this

Published by Bioscientifica Ltd 
construct into the growth plate injury site of a miniature pig model, Planka et al. (2012) observed some success in preventing limb length discrepancy as well as minimising angulation deformities. In addition, the injury sites also showed signs of hyaline-type cartilage repair (Planka et al. 2012). An earlier study by Li et al. (2004) in a rabbit growth plate injury model also found some success with MSCs embedded in chitosan gel in correcting angulation deformity and length discrepancy in their rabbit growth plate model following the removal of the initial bone bridge. Furthermore, Schmitt et al. (2012) observed that following sequential additions of both TGFB and BMP2, BMMSCs in an agarose scaffold formed differentiated chondrocytes in vitro with zonal alignment, which mimic growth plate-like zonal structure. However, more studies are still required to find the optimal combination of MSCs, growth factors, and supporting matrix scaffold to induce regeneration of injured growth plate cartilage with proper zonal structure and functional recovery.

\section{Potential in situ approach for growth plate regeneration mobilising endogenous MSCs}

Although autologous or allogeneic MSC transplantations offer a clear advantage over direct chondrocyte transplantation for potential growth plate regeneration, there are still many limitations with their use, including laborious isolation and ex vivo expansion, time required to have sufficient numbers of cells for transplantation, the need for ingredients such as foetal calf serum, associated expenses and potential immunoregulatory issues following implantation (Xian \& Foster 2006). Since bone formation and bony repair occur rapidly within the growth plate injury site (starting after 1 week following the injury), there is the possibility that the long length of time it takes for MSC harvest, in vitro expansion and implantation could limit the usefulness of this in vitro MSC expansion/transplantation cell-based therapy for growth plate regeneration initially after growth plate injuries. Ultimately, potential mobilisation and use of a patient's own endogenous MSCs to regenerate the growth plate injury site immediately following injury would be ideal with the development of an in situ endogenous progenitor cell therapy, which can potentially circumvent all these limitations of the in vitro MSC approach (De Bari et al. 2003, Evans et al. 2007) as well as the need for the surgical removal of the formed bony repair tissue later on. However, more work in future on this area is needed to identify the most optimal signals and support to mobilise sufficient amounts of endogenous MSCs into the growth plate injury site and promote their expansion and cartilage regeneration at the growth plate injury site.

\section{More studies in large animal models}

While tissue engineering/cell therapy has become a promising way of enabling growth plate regeneration in growth plate injury repair models in rabbits, more studies are needed to be carried out in large animal models that would mimic human growth plate anatomy, regeneration potentials and clinical outcomes more closely. Currently, there are only very limited studies that have examined the effects of chondrocyte transplantation as well as MSC transplantation using the ovine growth plate injury model, which saw limited success in growth plate regeneration using implanted chondrocytes or autologous MSCs (Foster et al. 1990, McCarty et al. 2010). Although direct transplantation of growth plate chondrocytes elucidated some positive effects including the prevention of bony repair tissue, the cellular survival rates of the implants were unpredictable, making them not ideal for clinical use (Foster et al. 1990). On the other hand, following autologous MSC transplantation in the presence of exogenous TGFB1 in this ovine growth plate injury model, McCarty et al. (2010) observed undesirable fibrous tissue formation rather than cartilage regeneration. Overall, the above studies in the larger animal models have not resulted inasmuch success and positive outcomes as observed in similar growth plate injury models in rabbits. This highlights the need for the use of larger animal models to evaluate tissue engineering constructs/MSCbased cell therapies in regenerating injured growth plate cartilage before an optimal MSC-based cell therapy can be developed for human usage.

\section{Conclusions}

Injuries to the growth plate are common occurrences and in many cases will result in undesirable bony repair at the injury site causing bone growth defects and lifelong orthopaedic problems. While the currently used surgical techniques can to some extent 'correct' some associated orthopaedic issues, they are highly invasive and often ineffective requiring repeated procedures. In the last 15 years, experimental studies with animal models such as the rat growth plate injury model have been able to observe the phases of growth plate injury repair responses leading to the undesirable bony repair at the injured growth plate. In addition, recent studies in a rat growth plate injury remodel have uncovered the important roles of PDGF as a potent chemotactic agent

Published by Bioscientifica Ltd 
promoting infiltration/proliferation of mesenchymal progenitor cells, osteoprogenitors and/or chondroprogenitors into the injury site as well as the critical role of VEGF as a key angiogenic factor involved in new blood vessel formation important for the bony repair of the injured growth plate. Furthermore, recent work has identified up-regulation of both BMP and Wnt/B-catenin signalling pathways accompanying the osteogenesis response at the injured growth plate and blockage of B-catenin signalling has been shown to inhibit the undesirable bone bridge formation. The findings of these important signals for bony repair represent some advances in the understanding of the mechanisms for growth plate bony repair. They, in combination with recent cartilage tissue engineering advances, could also potentially be explored in future studies for the development of an in situ cell-based therapy for growth plate regeneration. In addition, these new findings of the signals important for growth plate bony repair can also be explored by the current MSC-based tissue engineering approach for identifying potential 'optimal growth factors and osteogenesis/angiogenesis inhibitors' so to enhance the likely success of the implanted exogenously expanded MSCs in regenerating the injured growth plate. Further work is required to study the molecular signals that lead to growth plate bony repair. Additional studies are required to find the appropriate and most optimal combination of chemotactic growth factors and scaffolds that will aid in devising an in situ biological strategy mobilising endogenous MSCs for blocking bony repair and inducing growth plate regeneration. Furthermore, although there have been many promising results in smaller growth plate injury models (such as the rabbit), more studies in larger animals are required to investigate the therapeutic effectiveness of MSC-based therapies.

\section{Declaration of interest}

The authors declare that there is no conflict of interest that could be perceived as prejudicing the impartiality of the review.

\section{Funding}

The authors' own work reviewed in this article was funded in parts by grants from the Bone Health Foundation, Channel-7 Children's Research Foundation of South Australia and the Australian National Health and Medical Research Council (NHMRC). C J X is a NHMRC Senior Research Fellow.

\section{References}

Abad V, Meyers JL, Weise M, Gafni RI, Barnes KM, Nilsson O, Bacher JD \& Baron $\mathrm{J} 2002$ The role of the resting zone in growth plate chondrogenesis. Endocrinology 143 1851-1857. (doi:10.1210/endo.143.5.8776)
Ahn JI, Terry Canale S, Butler SD \& Hasty KA 2004 Stem cell repair of physeal cartilage. Journal of Orthopaedic Research 22 1215-1221. (doi:10.1016/j.orthres.2004.03.012)

Arasapam G, Scherer M, Cool JC, Foster BK \& Xian CJ 2006 Roles of COX-2 and iNOS in the bony repair of the injured growth plate cartilage. Journal of Cellular Biochemistry 99 450-461. (doi:10.1002/jcb.20905)

Baker J, Liu JP, Robertson EJ \& Efstratiadis A 1993 Role of insulin-like growth factors in embryonic and postnatal growth. Cell 75 73-82. (doi:10.1016/0092-8674(93)90680-O)

Barmada A, Gaynor T \& Mubarak SJ 2003 Premature physeal closure following distal tibia physeal fractures: a new radiographic predictor. Journal of Pediatric Orthopedics 23 733-739. (doi:10.1097/01241398200311000-00010)

Barnes GL, Kostenuik PJ, Gerstenfeld LC \& Einhorn TA 1999 Growth factor regulation of fracture repair. Journal of Bone and Mineral Research $\mathbf{1 4}$ 1805-1815. (doi:10.1359/jbmr.1999.14.11.1805)

Basener CJ, Mehlman CT \& DiPasquale TG 2009 Growth disturbance after distal femoral growth plate fractures in children: a meta-analysis. Journal of Orthopaedic Trauma 23 663-667. (doi:10.1097/BOT.0b013e3181a4f25b)

Baumgart R 2009 The reverse planning method for lengthening of the lower limb using a straight intramedullary nail with or without deformity correction. A new method. Operative Orthopädie und Traumatologie 21 221-233. (doi:10.1007/s00064-009-1709-4)

Bentley G \& Greer RB III 1971 Homotransplantation of isolated epiphyseal and articular cartilage chondrocytes into joint surfaces of rabbits. Nature 230 385-388. (doi:10.1038/230385a0)

Bordei P 2011 Locally applied platelet-derived growth factor accelerates fracture healing. Journal of Bone and Joint Surgery 93 1653-1659. (doi:10.1302/0301-620X.93B12.27244)

Brandi ML \& Collin-Osdoby P 2006 Vascular biology and the skeleton. Journal of Bone and Mineral Research 21 183-192. (doi:10.1359/JBMR.050917)

Brown JH \& DeLuca SA 1992 Growth plate injuries: Salter-Harris classification. American Family Physician 46 1180-1184.

Caplan AI 1991 Mesenchymal stem cells. Journal of Orthopaedic Research 9 641-650. (doi:10.1002/jor.1100090504)

Celil AB \& Campbell PG 2005 BMP-2 and insulin-like growth factor-I mediate osterix (Osx) expression in human mesenchymal stem cells via the MAPK and protein kinase D signaling pathways. Journal of Biological Chemistry 280 31353-31359. (doi:10.1074/jbc.M503845200)

Chen F, Hui JH, Chan WK \& Lee EH 2003 Cultured mesenchymal stem cell transfers in the treatment of partial growth arrest. Journal of Pediatric Orthopedics 23 425-429.

Chen D, Zhao M \& Mundy GR 2004 Bone morphogenetic proteins. Growth Factors 22 233-241. (doi:10.1080/08977190412331279890)

Chen Y, Whetstone HC, Lin AC, Nadesan P, Wei Q, Poon R \& Alman BA $2007 \beta$-Catenin signaling plays a disparate role in different phases of fracture repair: implications for therapy to improve bone healing. PLoS Medicine 4 e249. (doi:10.1371/journal.pmed.0040249)

Cheng CC, Lian WS, Hsiao FS, Liu IH, Lin SP, Lee YH, Chang CC, Xiao GY, Huang HY, Cheng CF et al. 2012 Isolation and characterization of novel murine epiphysis derived mesenchymal stem cells. PLOS ONE 7 e36085. (doi:10.1371/journal.pone.0036085)

Chim SM, Tickner J, Chow ST, Kuek V, Guo B, Zhang G, Rosen V, Erber W \& $\mathrm{Xu} \mathrm{J} 2013$ Angiogenic factors in bone local environment. Cytokine \& Growth Factor Reviews 24 297-310. (doi:10.1016/j.cytogfr.2013.03.008)

Chung C \& Burdick JA 2009 Influence of three-dimensional hyaluronic acid microenvironments on mesenchymal stem cell chondrogenesis. Tissue Engineering. Part A 15 243-254. (doi:10.1089/ten.tea.2008.0067)

Chung R, Cool JC, Scherer MA, Foster BK \& Xian CJ 2006 Roles of neutrophil-mediated inflammatory response in the bony repair of injured growth plate cartilage in young rats. Journal of Leukocyte Biology 80 1272-1280. (doi:10.1189/jlb.0606365)

Chung R, Foster BK, Zannettino AC \& Xian CJ 2009 Potential roles of growth factor PDGF-BB in the bony repair of injured growth plate. Bone 44 878-885. (doi:10.1016/j.bone.2009.01.377) 
Chung R, Foster BK \& Xian CJ 2013a Inhibition of protein kinase-D promotes cartilage repair at injured growth plate in rats. Injury $\mathbf{4 4}$ 914-922. (doi:10.1016/j.injury.2013.01.038)

Chung R, Wong D, Macsai C, Piergentili A, Del Bello F, Quaglia W \& Xian CJ $2013 b$ Roles of Wnt/ $\beta$-catenin signalling pathway in the bony repair of injured growth plate cartilage in young rats. Bone 52 651-658 (doi:10.1016/j.bone.2012.10.035)

Chung R, Foster BK \& Xian CJ 2014 The potential role of VEGF-induced vascularisation in the bony repair of injured growth plate. Journal of Endocrinology 221 63-75. (doi:10.1530/JOE-13-0539)

Coleman RM, Case ND \& Guldberg RE 2007 Hydrogel effects on bone marrow stromal cell response to chondrogenic growth factors. Biomaterials 28 2077-2086. (doi:10.1016/j.biomaterials.2007.01.010)

Coleman RM, Phillips JE, Lin A, Schwartz Z, Boyan BD \& Guldberg RE 2010 Characterization of a small animal growth plate injury model using microcomputed tomography. Bone 46 1555-1563. (doi:10.1016/j.bone. 2010.02.017)

Coleman RM, Schwartz Z, Boyan BD \& Guldberg RE 2013 The therapeutic effect of bone marrow-derived stem cell implantation after epiphyseal plate injury is abrogated by chondrogenic predifferentiation. Tissue Engineering. Part A 19 475-483. (doi:10.1089/ten.tea.2012.0125)

Dai J \& Rabie AB 2007 Recombinant adeno-associated virus vector hybrids efficiently target different skeletal cells. Frontiers in Bioscience $\mathbf{1 2}$ 4280-4287. (doi:10.2741/2387)

Dao DY, Jonason JH, Zhang Y, Hsu W, Chen D, Hilton MJ \& O'Keefe RJ 2012 Cartilage-specific $\beta$-catenin signaling regulates chondrocyte maturation, generation of ossification centers, and perichondrial bone formation during skeletal development. Journal of Bone and Mineral Research 27 1680-1694. (doi:10.1002/jbmr.1639)

Day TF, Guo X, Garrett-Beal L \& Yang Y 2005 Wnt/B-catenin signaling in mesenchymal progenitors controls osteoblast and chondrocyte differentiation during vertebrate skeletogenesis. Developmental Cell 8 739-750. (doi:10.1016/j.devcel.2005.03.016)

De Bari C, Dell'Accio F, Vandenabeele F, Vermeesch JR, Raymackers JM \& Luyten FP 2003 Skeletal muscle repair by adult human mesenchymal stem cells from synovial membrane. Journal of Cell Biology 160 909-918. (doi:10.1083/jcb.200212064)

Detterline AJ, Goldberg S, Bach BR Jr \& Cole BJ 2005 Treatment options for articular cartilage defects of the knee. Orthopedic Nursing 24 361-366 (quiz 367-368).

Dimitriou R, Tsiridis E \& Giannoudis PV 2005 Current concepts of molecular aspects of bone healing. Injury 36 1392-1404. (doi:10.1016/ j.injury.2005.07.019)

Drury JL \& Mooney DJ 2003 Hydrogels for tissue engineering: scaffold design variables and applications. Biomaterials 24 4337-4351. (doi:10.1016/S0142-9612(03)00340-5)

Du X, Xie Y, Xian CJ \& Chen L 2012 Role of FGFs/FGFRs in skeletal development and bone regeneration. Journal of Cellular Physiology 227 3731-3743. (doi:10.1002/jcp.24083)

Eid AM \& Hafez MA 2002 Traumatic injuries of the distal femoral physis. Retrospective study on 151 cases. Injury 33 251-255. (doi:10.1016/ S0020-1383(01)00109-7)

Elangovan S, D'Mello SR, Hong L, Ross RD, Allamargot C, Dawson DV, Stanford CM, Johnson GK, Sumner DR \& Salem AK 2014 The enhancement of bone regeneration by gene activated matrix encoding for platelet derived growth factor. Biomaterials 35 737-747. (doi:10.1016/j.biomaterials.2013.10.021)

Emad B, Sherifel M, Basma GM, Wong RW, Bendeus M \& Rabie AB 2006 Vascular endothelial growth factor augments the healing of demineralized bone matrix grafts. International Journal of Surgery 4 160-166. (doi:10.1016/j.ijsu.2006.04.005)

Evans CH, Palmer GD, Pascher A, Porter R, Kwong FN, Gouze E, Gouze JN, Liu F, Steinert A, Betz O et al. 2007 Facilitated endogenous repair: making tissue engineering simple, practical, and economical. Tissue Engineering 13 1987-1993. (doi:10.1089/ten.2006.0302)
Feghali CA \& Wright TM 1997 Cytokines in acute and chronic inflammation. Frontiers in Bioscience 2 d12-d26.

Fischerauer E, Heidari N, Neumayer B, Deutsch A \& Weinberg AM 2011 The spatial and temporal expression of VEGF and its receptors 1 and 2 in post-traumatic bone bridge formation of the growth plate. Journal of Molecular Histology 42 513-522. (doi:10.1007/s10735-011-9359-x)

Fischerauer EE, Manninger M, Seles M, Janezic G, Pichler K, Ebner B \& Weinberg AM 2013 BMP-6 and BMPR-1a are up-regulated in the growth plate of the fractured tibia. Journal of Orthopaedic Research 31 357-363. (doi:10.1002/jor.22238)

Forriol F \& Shapiro F 2005 Bone development: interaction of molecular components and biophysical forces. Clinical Orthopaedics and Related Research 432 14-33. (doi:10.1097/01.blo.0000156001.78631.e9)

Foster BK, Hansen AL, Gibson GJ, Hopwood JJ, Binns GF \& Wiebkin OW 1990 Reimplantation of growth plate chondrocytes into growth plate defects in sheep. Journal of Orthopaedic Research 8 555-564. (doi:10.1002/jor.1100080412)

Fu X, Han B, Cai S, Lei Y, Sun T \& Sheng Z 2009 Migration of bone marrowderived mesenchymal stem cells induced by tumor necrosis factor- $\alpha$ and its possible role in wound healing. Wound Repair and Regeneration 17 185-191. (doi:10.1111/j.1524-475X.2009.00454.x)

Fukumoto T, Sperling JW, Sanyal A, Fitzsimmons JS, Reinholz GG, Conover CA \& O'Driscoll SW 2003 Combined effects of insulin-like growth factor- 1 and transforming growth factor- $\beta 1$ on periosteal mesenchymal cells during chondrogenesis in vitro. Osteoarthritis and Cartilage $\mathbf{1 1}$ 55-64. (doi:10.1053/joca.2002.0869)

Gerber HP, Vu TH, Ryan AM, Kowalski J, Werb Z \& Ferrara N 1999 VEGF couples hypertrophic cartilage remodeling, ossification and angiogenesis during endochondral bone formation. Nature Medicine 5 623-628. (doi:10.1038/9467)

Gerstenfeld LC, Cho TJ, Kon T, Aizawa T, Cruceta J, Graves BD \& Einhorn TA 2001 Impaired intramembranous bone formation during bone repair in the absence of tumor necrosis factor- $\alpha$ signaling. Cells, Tissues, Organs 169 285-294. (doi:10.1159/000047893)

Gerstenfeld LC, Cho TJ, Kon T, Aizawa T, Tsay A, Fitch J, Barnes GL, Graves DT \& Einhorn TA 2003 Impaired fracture healing in the absence of TNF- $\alpha$ signaling: the role of TNF- $\alpha$ in endochondral cartilage resorption. Journal of Bone and Mineral Research 18 1584-1592. (doi:10.1359/jbmr.2003.18.9.1584)

Ghodadra N \& Singh K 2008 Recombinant human bone morphogenetic protein-2 in the treatment of bone fractures. Biologics 2 345-354.

Golovchenko S, Hattori T, Hartmann C, Gebhardt M, Gebhard S, Hess A, Pausch F, Schlund B \& von der Mark K 2013 Deletion of $\beta$ catenin in hypertrophic growth plate chondrocytes impairs trabecular bone formation. Bone 55 102-112. (doi:10.1016/j.bone.2013.03.019)

Horowitz MC, Xi Y, Wilson K \& Kacena MA 2001 Control of osteoclastogenesis and bone resorption by members of the TNF family of receptors and ligands. Cytokine \& Growth Factor Reviews 12 9-18. (doi:10.1016/ S1359-6101(00)00030-7)

Hui JH, Li L, Teo YH, Ouyang HW \& Lee EH 2005 Comparative study of the ability of mesenchymal stem cells derived from bone marrow, periosteum, and adipose tissue in treatment of partial growth arrest in rabbit. Tissue Engineering 11 904-912. (doi:10.1089/ten.2005.11.904)

Hunziker EB, Wagner J \& Zapf J 1994 Differential effects of insulin-like growth factor I and growth hormone on developmental stages of rat growth plate chondrocytes in vivo. Journal of Clinical Investigation 93 1078-1086. (doi:10.1172/JCI117058)

Hutmacher DW 2000 Scaffolds in tissue engineering bone and cartilage. Biomaterials 21 2529-2543. (doi:10.1016/S0142-9612(00)00121-6)

Iannotti JP 1990 Growth plate physiology and pathology. Orthopedic Clinics of North America 21 1-17.

Indrawattana N, Chen G, Tadokoro M, Shann LH, Ohgushi H, Tateishi T, Tanaka J \& Bunyaratvej A 2004 Growth factor combination for chondrogenic induction from human mesenchymal stem cell. Biochemical and Biophysical Research Communications 320 914-919. (doi:10.1016/j.bbrc.2004.06.029) 
Jaklenec A, Hinckfuss A, Bilgen B, Ciombor DM, Aaron R \& Mathiowitz E 2008 Sequential release of bioactive IGF-I and TGF- $\beta 1$ from PLGA microsphere-based scaffolds. Biomaterials 29 1518-1525. (doi:10.1016/ j.biomaterials.2007.12.004)

Jaramillo D, Shapiro F, Hoffer FA, Winalski CS, Koskinen MF, Frasso R \& Johnson A 1990 Posttraumatic growth-plate abnormalities: MR imaging of bony-bridge formation in rabbits. Radiology 175 767-773.

Jensen ED, Gopalakrishnan R \& Westendorf JJ 2009 Bone morphogenic protein 2 activates protein kinase $\mathrm{D}$ to regulate histone deacetylase 7 localization and repression of Runx2. Journal of Biological Chemistry $\mathbf{2 8 4}$ 2225-2234. (doi:10.1074/jbc.M800586200)

Jin XB, Luo ZJ \& Wang J 2006 Treatment of rabbit growth plate injuries with an autologous tissue-engineered composite. An experimental study. Cells, Tissues, Organs 183 62-67. (doi:10.1159/000095510)

Jing J, Ren Y, Zong Z, Liu C, Kamiya N, Mishina Y, Liu Y, Zhou X \& Feng JQ 2013 BMP receptor 1A determines the cell fate of the postnatal growth plate. International Journal of Biological Sciences 9 895-906. (doi:10.7150/ ijbs.7508)

Johnstone B, Hering TM, Caplan AI, Goldberg VM \& Yoo JU 1998 In vitro chondrogenesis of bone marrow-derived mesenchymal progenitor cells. Experimental Cell Research 238 265-272. (doi:10.1006/excr.1997.3858)

Kaback LA, Soung do Y, Naik A, Smith N, Schwarz EM, O'Keefe RJ \& Drissi H 2008 Osterix/Sp7 regulates mesenchymal stem cell mediated endochondral ossification. Journal of Cellular Physiology 214 173-182. (doi:10.1002/jcp.21176)

Kay RM \& Matthys GA 2001 Pediatric ankle fractures: evaluation and treatment. Journal of the American Academy of Orthopaedic Surgeons 9 268-278.

Kirker-head CA \& Gerhart TN 1998 Healing bone using recombinant human bone morphogenetic protein 2 and copolymer. Clinical Orthopaedics and Related Research 205217.

Komori T, Yagi H, Nomura S, Yamaguchi A, Sasaki K, Deguchi K, Shimizu Y, Bronson RT, Gao YH, Inada M et al. 1997 Targeted disruption of Cbfa1 results in a complete lack of bone formation owing to maturational arrest of osteoblasts. Cell 89 755-764. (doi:10.1016/S00928674(00)80258-5)

Koo SK, Kim SC, Wee YM, Kim YH, Jung EJ, Choi MY, Park YH, Park KT, Lim DG \& Han DJ 2008 Experimental microencapsulation of porcine and rat pancreatic islet cells with air-driven droplet generator and alginate. Transplantation Proceedings 40 2578-2580. (doi:10.1016/ j.transproceed.2008.08.019)

Korsak J, Rzeszotarska A, Marczynski W, Jablonska I, Bialecki J \& Walczak P 2013 Concentration of platelet derived-growth factors in concentrates used to regenerate injured bone tissue. Ortopedia, Traumatologia, Rehabilitacja 15 379-388. (doi:10.5604/15093492.1084239)

Langenskiold A 1981 Surgical treatment of partial closure of the growth plate. Journal of Pediatric Orthopedics 1 3-11. (doi:10.1097/01241398198101010-00002)

Leary JT, Handling M, Talerico M, Yong L \& Bowe JA 2009 Physeal fractures of the distal tibia: predictive factors of premature physeal closure and growth arrest. Journal of Pediatric Orthopedics 29 356-361. (doi:10.1097/ BPO.0b013e3181a6bfe8)

Lee EH, Gao GX \& Bose K 1993 Management of partial growth arrest: physis, fat, or silastic? Journal of Pediatric Orthopedics 13 368-372. (doi:10.1097/01241398-199305000-00018)

Lee EH, Chen F, Chan J \& Bose K 1998 Treatment of growth arrest by transfer of cultured chondrocytes into physeal defects. Journal of Pediatric Orthopedics 18 155-160.

Lee MA, Nissen TP \& Otsuka NY 2000 Utilization of a murine model to investigate the molecular process of transphyseal bone formation. Journal of Pediatric Orthopedics 20 802-806. (doi:10.1097/01241398200011000-00021)

Lee CW, Martinek V, Usas A, Musgrave D, Pickvance EA, Robbins P, Moreland MS, Fu FH \& Huard J 2002 Muscle-based gene therapy and tissue engineering for treatment of growth plate injuries. Journal of Pediatric Orthopaedics 22 565-572.
Lennon DP, Haynesworth SE, Young RG, Dennis JE \& Caplan AI 1995 A chemically defined medium supports in vitro proliferation and maintains the osteochondral potential of rat marrow-derived mesenchymal stem cells. Experimental Cell Research 219 211-222. (doi:10.1006/excr.1995.1221)

Li L, Hui JH, Goh JC, Chen F \& Lee EH 2004 Chitin as a scaffold for mesenchymal stem cells transfers in the treatment of partial growth arrest. Journal of Pediatric Orthopedics 24 205-210. (doi:10.1097/ 01241398-200403000-00014)

Li R, Stewart DJ, von Schroeder HP, Mackinnon ES \& Schemitsch EH 2009 Effect of cell-based VEGF gene therapy on healing of a segmental bone defect. Journal of Orthopaedic Research 27 8-14. (doi:10.1002/jor.20658)

Li W-C, Xu R-J, Xue Y-L, Huang J-X \& Gao Y-H 2013 Treatment of growth plate injury with microencapsulated chondrocytes. Biotechnology and Bioprocess Engineering 18 655-662. (doi:10.1007/s12257-012-0451-1)

Lu C, Wan Y, Cao J, Zhu X, Yu J, Zhou R, Yao Y, Zhang L, Zhao H, Li H et al. 2013 Wnt-mediated reciprocal regulation between cartilage and bone development during endochondral ossification. Bone $\mathbf{5 3} 566-574$. (doi:10.1016/j.bone.2012.12.016)

Macsai CE, Foster BK \& Xian CJ 2008 Roles of Wnt signalling in bone growth, remodelling, skeletal disorders and fracture repair. Journal of Cellular Physiology 215 578-587. (doi:10.1002/jcp.21342)

Macsai CE, Hopwood B, Chung R, Foster BK \& Xian CJ 2011 Structural and molecular analyses of bone bridge formation within the growth plate injury site and cartilage degeneration at the adjacent uninjured area. Bone 49 904-912. (doi:10.1016/j.bone.2011.07.024)

Macsai CE, Georgiou KR, Foster BK, Zannettino AC \& Xian CJ 2012 Microarray expression analysis of genes and pathways involved in growth plate cartilage injury responses and bony repair. Bone $\mathbf{5 0}$ 1081-1091. (doi:10.1016/j.bone.2012.02.013)

Mancilla EE, De Luca F, Uyeda JA, Czerwiec FS \& Baron J 1998 Effects of fibroblast growth factor-2 on longitudinal bone growth. Endocrinology 139 2900-2904.

Mann DC \& Rajmaira S 1990 Distribution of physeal and nonphyseal fractures in 2,650 long-bone fractures in children aged 0-16 years. Journal of Pediatric Orthopedics 10 713-716. (doi:10.1097/01241398199011000-00002)

Marsell R \& Einhorn TA 2009 The role of endogenous bone morphogenetic proteins in normal skeletal repair. Injury 40 (Suppl 3) S4-S7. (doi:10.1016/S0020-1383(09)70003-8)

Martin P, D'Souza D, Martin J, Grose R, Cooper L, Maki R \& McKercher SR 2003 Wound healing in the PU.1 null mouse-tissue repair is not dependent on inflammatory cells. Current Biology 13 1122-1128. (doi:10.1016/S0960-9822(03)00396-8)

McCarty RC, Gronthos S, Zannettino AC, Foster BK \& Xian CJ 2009 Characterisation and developmental potential of ovine bone marrow derived mesenchymal stem cells. Journal of Cellular Physiology 219 324-333. (doi:10.1002/jcp.21670)

McCarty RC, Xian CJ, Gronthos S, Zannettino AC \& Foster BK 2010 Application of autologous bone marrow derived mesenchymal stem cells to an ovine model of growth plate cartilage injury. Open Orthopaedics Journal 4 204-210. (doi:10.2174/1874325001004010204)

Minina E, Kreschel C, Naski MC, Ornitz DM \& Vortkamp A 2002 Interaction of FGF, Ihh/Pthlh, and BMP signaling integrates chondrocyte proliferation and hypertrophic differentiation. Developmental Cell 3 439-449. (doi:10.1016/S1534-5807(02)00261-7)

Miura Y, Parvizi J, Fitzsimmons JS \& O’Driscoll SW 2002 Brief exposure to highdose transforming growth factor- $\beta 1$ enhances periosteal chondrogenesis in vitro: a preliminary report. Journal of Bone and Joint Surgery 84-A 793-799.

Mizuta T, Benson WM, Foster BK, Paterson DC \& Morris LL 1987 Statistical analysis of the incidence of physeal injuries. Journal of Pediatric Orthopedics 7 518-523. (doi:10.1097/01241398-198709000-00003)

Mubarak SJ, Kim JR, Edmonds EW, Pring ME \& Bastrom TP 2009 Classification of proximal tibial fractures in children. Journal of Children's Orthopaedics 3 191-197. (doi:10.1007/s11832-009-0167-8) 
Murakami N, Saito N, Horiuchi H, Okada T, Nozaki K \& Takaoka K 2002 Repair of segmental defects in rabbit humeri with titanium fiber mesh cylinders containing recombinant human bone morphogenetic protein-2 (rhBMP-2) and a synthetic polymer. Journal of Biomedical Materials Research 62 169-174. (doi:10.1002/jbm.10236)

Musumeci G, Castrogiovanni P, Loreto C, Castorina S, Pichler K \& Weinberg AM 2013 Post-traumatic caspase-3 expression in the adjacent areas of growth plate injury site: a morphological study. International Journal of Molecular Sciences 14 15767-15784. (doi:10.3390/ijms140815767)

Nakashima K, Zhou X, Kunkel G, Zhang Z, Deng JM, Behringer RR \& de Crombrugghe B 2002 The novel zinc finger-containing transcription factor osterix is required for osteoblast differentiation and bone formation. Cell 108 17-29. (doi:10.1016/S0092-8674(01)00622-5)

Ngo TQ, Scherer MA, Zhou FH, Foster BK \& Xian CJ 2006 Expression of bone morphogenic proteins and receptors at the injured growth plate cartilage in young rats. Journal of Histochemistry and Cytochemistry $\mathbf{5 4}$ 945-954. (doi:10.1369/jhc.6A6939.2006)

Ogden JA 1984 Growth slowdown and arrest lines. Journal of Pediatric Orthopedics 4 409-415. (doi:10.1097/01241398-198408000-00003)

Odgen JA 2000 Anatomy and physiology of skeletal development. In Skeletal Injuries in the Child, 3rd edn., pp 1-38. New York, NY, USA: Springer-Verlag.

Park J, Gelse K, Frank S, von der Mark K, Aigner T \& Schneider H 2006 Transgene-activated mesenchymal cells for articular cartilage repair: a comparison of primary bone marrow-, perichondrium/periosteum- and fat-derived cells. Journal of Gene Medicine 8112-125. (doi:10.1002/jgm.826)

Planka L, Gal P, Kecova H, Klima J, Hlucilova J, Filova E, Amler E, Krupa P, Kren L, Srnec R et al. 2008 Allogeneic and autogenous transplantations of MSCs in treatment of the physeal bone bridge in rabbits. BMC Biotechnology 8 70. (doi:10.1186/1472-6750-8-70)

Planka L, Srnec R, Rauser P, Stary D, Filova E, Jancar J, Juhasova J, Kren L, Necas A \& Gal P 2012 Nanotechnology and mesenchymal stem cells with chondrocytes in prevention of partial growth plate arrest in pigs. Biomedical Papers of the Medical Faculty of the University Palacky, Olomouc, Czechoslovakia 156 128-134. (doi:10.5507/bp.2012.041)

Provot S \& Schipani E 2005 Molecular mechanisms of endochondral bone development. Biochemical and Biophysical Research Communications 328 658-665. (doi:10.1016/j.bbrc.2004.11.068)

Revell CM \& Athanasiou KA 2009 Success rates and immunologic responses of autogenic, allogenic, and xenogenic treatments to repair articular cartilage defects. Tissue Engineering. Part B, Reviews 15 1-15. (doi:10.1089/ten.teb.2008.0189)

Sailhan F, Chotel F, Guibal AL, Gollogly S, Adam P, Berard J \& Guibaud L 2004 Three-dimensional MR imaging in the assessment of physeal growth arrest. European Radiology 14 1600-1608. (doi:10.1007/s00330004-2319-z)

Sakaguchi Y, Sekiya I, Yagishita K \& Muneta T 2005 Comparison of human stem cells derived from various mesenchymal tissues: superiority of synovium as a cell source. Arthritis and Rheumatism 52 2521-2529. (doi:10.1002/art.21212)

Sakou T 1998 Bone morphogenetic proteins: from basic studies to clinical approaches. Bone 22 591-603. (doi:10.1016/S8756-3282(98)00053-2)

Schindeler A, McDonald MM, Bokko P \& Little DG 2008 Bone remodeling during fracture repair: the cellular picture. Seminars in Cell \& Developmental Biology 19 459-466. (doi:10.1016/j.semcdb.2008.07.004)

Schmitt JF, See KH, Yang Z, Hui JH \& Lee EH 2012 Sequential differentiation of mesenchymal stem cells in an agarose scaffold promotes a physis-like zonal alignment of chondrocytes. Journal of Orthopaedic Research $\mathbf{3 0}$ 1753-1759. (doi:10.1002/jor.22123)

Solchaga LA, Penick K, Porter JD, Goldberg VM, Caplan AI \& Welter JF 2005 FGF-2 enhances the mitotic and chondrogenic potentials of human adult bone marrow-derived mesenchymal stem cells. Journal of Cellular Physiology 203 398-409. (doi:10.1002/jcp.20238)

Street J, Bao M, deGuzman L, Bunting S, Peale FV Jr, Ferrara N, Steinmetz H, Hoeffel J, Cleland JL, Daugherty A et al. 2002 Vascular endothelial growth factor stimulates bone repair by promoting angiogenesis and bone turnover. PNAS 99 9656-9661. (doi:10.1073/pnas.152324099)

Sundararaj SK, Cieply RD, Gupta G, Milbrandt TA \& Puleo DA 2012 Treatment of growth plate injury using IGF-I-loaded PLGA scaffolds. Journal of Tissue Engineering and Regenerative Medicine [in press]. (doi:10.1002/term.1670)

Tang QO, Shakib K, Heliotis M, Tsiridis E, Mantalaris A, Ripamonti U \& Tsiridis E 2009 TGF- $\beta 3$ : a potential biological therapy for enhancing chondrogenesis. Expert Opinion on Biological Therapy 9 689-701. (doi:10.1517/14712590902936823)

Tobita M, Ochi M, Uchio Y, Mori R, Iwasa J, Katsube K \& Motomura T 2002 Treatment of growth plate injury with autogenous chondrocytes: a study in rabbits. Acta Orthopaedica Scandinavica 73 352-358. (doi:10.1080/000164702320155383)

Toolan BC, Frenkel SR, Pereira DS \& Alexander H 1998 Development of a novel osteochondral graft for cartilage repair. Journal of Biomedical Materials Research 41 244-250. (doi:10.1002/(SICI)10974636(199808)41:2<244::AID-JBM9>3.0.CO;2-I)

Tsuji K, Bandyopadhyay A, Harfe BD, Cox K, Kakar S, Gerstenfeld L, Einhorn T, Tabin CJ \& Rosen V 2006 BMP2 activity, although dispensable for bone formation, is required for the initiation of fracture healing. Nature Genetics 38 1424-1429. (doi:10.1038/ng1916)

Tu Q, Valverde P, Li S, Zhang J, Yang P \& Chen J 2007 Osterix overexpression in mesenchymal stem cells stimulates healing of critical-sized defects in murine calvarial bone. Tissue Engineering 13 2431-2440. (doi:10.1089/ten.2006.0406)

Vortkamp A, Lee K, Lanske B, Segre GV, Kronenberg HM \& Tabin CJ 1996 Regulation of rate of cartilage differentiation by Indian hedgehog and PTH-related protein. Science 273 613-622. (doi:10.1126/science.273. 5275.613)

Wattenbarger JM, Gruber HE \& Phieffer LS 2002 Physeal fractures, part I histologic features of bone, cartilage, and bar formation in a small animal model. Journal of Pediatric Orthopedics 22 703-709.

Worster AA, Nixon AJ, Brower-Toland BD \& Williams J 2000 Effect of transforming growth factor $\beta 1$ on chondrogenic differentiation of cultured equine mesenchymal stem cells. American Journal of Veterinary Research 61 1003-1010. (doi:10.2460/ajvr.2000.61.1003)

Worster AA, Brower-Toland BD, Fortier LA, Bent SJ, Williams J \& Nixon AJ 2001 Chondrocytic differentiation of mesenchymal stem cells sequentially exposed to transforming growth factor- $\beta 1$ in monolayer and insulin-like growth factor-I in a three-dimensional matrix. Journal of Orthopaedic Research 19 738-749. (doi:10.1016/S0736-0266 (00)00054-1)

Xian CJ 2007 Roles of epidermal growth factor family in the regulation of postnatal somatic growth. Endocrine Reviews 28 284-296. (doi:10.1210/ er.2006-0049)

Xian CJ \& Foster BK 2006 Repair of injured articular and growth plate cartilage using mesenchymal stem cells and chondrogenic gene therapy. Current Stem Cell Research \& Therapy 1 213-229. (doi:10.2174/ 157488806776956904)

Xian CJ, Zhou FH, McCarty RC \& Foster BK 2004 Intramembranous ossification mechanism for bone bridge formation at the growth plate cartilage injury site. Journal of Orthopaedic Research 22 417-426. (doi:10.1016/j.orthres.2003.08.003)

Xu B, Zhang J, Brewer E, Tu Q, Yu L, Tang J, Krebsbach P, Wieland M \& Chen J 2009 Osterix enhances BMSC-associated osseointegration of implants. Journal of Dental Research 88 1003-1007. (doi:10.1177/ 0022034509346928)

Yamaguchi A 1995 Regulation of differentiation pathway of skeletal mesenchymal cells in cell lines by transforming growth factor- $\beta$ superfamily. Seminars in Cell Biology 6 165-173. (doi:10.1006/scel. 1995.0023)

Yang X \& Karsenty G 2002 Transcription factors in bone: developmental and pathological aspects. Trends in Molecular Medicine 8 340-345. (doi:10.1016/S1471-4914(02)02340-7) 
Yang YQ, Tan YY, Wong R, Wenden A, Zhang LK \& Rabie AB 2012 The role of vascular endothelial growth factor in ossification. International Journal of Oral Science 4 64-68. (doi:10.1038/ijos.2012.33)

Yaoita H, Orimo H, Shirai Y \& Shimada T 2000 Expression of bone morphogenetic proteins and rat distal-less homolog genes following rat femoral fracture. Journal of Bone and Mineral Metabolism 18 63-70. (doi:10.1007/s007740050013)

Yoshida K, Higuchi C, Nakura A, Nakamura N \& Yoshikawa H 2012 Treatment of partial growth arrest using an in vitro-generated scaffold-free tissue-engineered construct derived from rabbit synovial mesenchymal stem cells. Journal of Pediatric Orthopedics 32 314-321. (doi:10.1097/BPO.0b013e31824afee3)
Zhou FH, Foster BK, Sander G \& Xian CJ 2004 Expression of proinflammatory cytokines and growth factors at the injured growth plate cartilage in young rats. Bone 35 1307-1315. (doi:10.1016/j.bone. 2004.09.014)

Zhou FH, Foster BK, Zhou XF, Cowin AJ \& Xian CJ 2006 TNF- $\alpha$ mediates p38 MAP kinase activation and negatively regulates bone formation at the injured growth plate in rats. Journal of Bone and Mineral Research $\mathbf{2 1}$ 1075-1088. (doi:10.1359/jbmr.060410)

Zhou X, Zhang Z, Feng JQ, Dusevich VM, Sinha K, Zhang H, Darnay BG \& de Crombrugghe B 2010 Multiple functions of osterix are required for bone growth and homeostasis in postnatal mice. PNAS $\mathbf{1 0 7}$ 12919-12924. (doi:10.1073/pnas.0912855107)

Received in final form 8 May 2014

Accepted 13 May 2014
๑) 2014 Society for Endocrinology Printed in Great Britain
Published by Bioscientifica Ltd 